\title{
Rho and Ras GTPases in Axon Growth, Guidance, and Branching
}

\author{
Alan Hall ${ }^{1}$ and Giovanna Lalli ${ }^{2}$ \\ ${ }^{1}$ Memorial Sloan-Kettering Cancer Center, Cell Biology Program, New York, New York 10065 \\ ${ }^{2}$ Wolfson Centre for Age-related Diseases, King's College London, London SE1 1UL, United Kingdom \\ Correspondence: giovanna.lalli@kcl.ac.uk
}

The establishment of precise neuronal cell morphology provides the foundation for all aspects of neurobiology. During development, axons emerge from cell bodies after an initial polarization stage, elongate, and navigate towards target regions guided by a range of environmental cues. The Rho and Ras families of small GTPases have emerged as critical players at all stages of axonogenesis. Their ability to coordinately direct multiple signal transduction pathways with precise spatial control drives many of the activities that underlie this morphogenetic program: the dynamic assembly, disassembly, and reorganization of the actin and microtubule cytoskeletons, the interaction of the growing axon with other cells and extracellular matrix, the delivery of lipids and proteins to the axon through the exocytic machinery, and the internalization of membrane and proteins at the leading edge of the growth cone through endocytosis. This article highlights the contribution of Rho and Ras GTPases to axonogenesis.

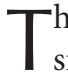
he Ras superfamily of small GTPases, consisting of almost 200 proteins, can be subclassified into six families: Rho, Ras, Rab, Arf, Sar, and Ran (Colicelli 2004). These proteins act as molecular switches, cycling between an inactive, GDP-bound state and an active, GTP-bound state (Fig. 1). The activated conformation interacts with specific effectors to propagate downstream signaling events that influence many aspects of cell biology. Guanine nucleotide exchange factors (GEFs) activate the switch by catalyzing the exchange of GDP for GTP, whereas GTPase-activating proteins (GAPs) increase the intrinsic GTPase activity and inactivate the switch (Fig. 1) (Jaffe and Hall 2005). Dominant-negative (DN) and constitutively active (CA) versions of small GTPases (created through specific amino acid substitutions) have been used extensively to dissect the individual roles of these proteins. Although these have been incredibly informative, they do have potential drawbacks: dominant-negative constructs, which act by sequestering GEFs, may interfere with closely related family members, whereas constitutively activated GTPases interact indiscriminately with all their potential targets, something that does not happen under normal conditions. RNAi and gene knockout

Editors: Marc Tessier-Lavigne and Alex L. Kolodkin

Additional Perspectives on Neuronal Guidance available at www.cshperspectives.org

Copyright (C) 2010 Cold Spring Harbor Laboratory Press; all rights reserved; doi: 10.1101/cshperspect.a001818

Cite this article as Cold Spring Harb Perspect Biol 2010;2:a001818 


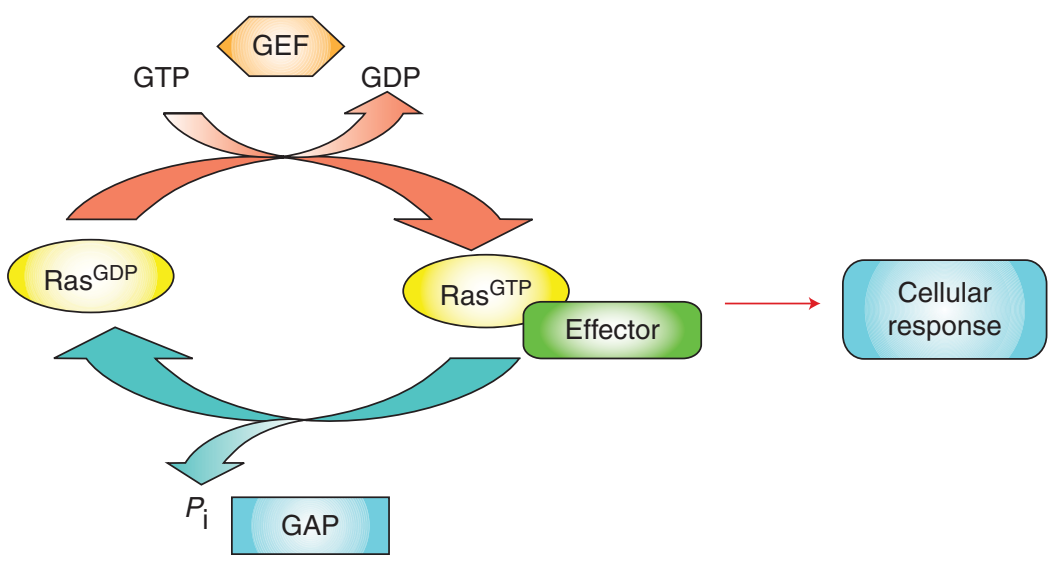

Figure 1. The GTPase cycle GTPases. (Ras, in this example) cycle between an inactive GDP-bound state and an active, GTP-bound state. Following a specific stimulus, GEFs catalyze the exchange of GDP for GTP, enabling the interaction of GTPases with specific effectors leading to cellular responses. In contrast, GAPs inactivate GTPases by stimulating their intrinsic GTPase activity.

approaches afford the potential for greater specificity, but they too have limitations, because GTPases, their regulators, and their targets are typically found as closely related isoforms. This article focuses on the role of Rho and Ras family members in four different aspects of axonogenesis: initiation, elongation, guidance, and branching. The major role of Rho GTPases, conserved in all eukaryotes, is to control the assembly, disassembly, and dynamic rearrangements of the actin and microtubule cytoskeletons. It is not surprising, therefore, that they play crucial roles in the growth, guidance, and branching of axons. Ras GTPases, on the other hand, are activated by a large number of plasma membrane growth factor receptors and adhesion receptors to promote key signal transduction pathways, including ERK, MAP kinase, and PI3-kinase, which play a variety of important roles in axonogenesis.

\section{INITIATING AN AXON}

The establishment and maintenance of neuronal polarity, morphologically visualized as a long, thin axon and several short, thicker dendrites, depend on coordinated cytoskeletal rearrangements and directed membrane trafficking. A more comprehensive review on the molecular pathways involved in neuronal polarity can be found elsewhere (Polleux and Snider 2010). Here, we focus on the specific roles played by Rho and Ras GTPases.

\section{Insights from Cell Culture Studies}

Cultured rodent hippocampal neurons have been used extensively to model neuronal polarization in vitro (Dotti et al. 1988). After the initial extension of thin filopodia (stage 1), two neurites emerge from opposite poles of the cell body, followed by the development of other short processes (stage 2). Half a day after plating, one of these minor neurites, usually one of the initial two sprouting processes, elongates and becomes the axon (stage 3) (Calderon de Anda et al. 2008). Four to 7 days later, the remaining minor neurites become mature dendrites (stage 4) and subsequently display dendritic spines (stage 5).

Five members of the Ras family, Ras, R-Ras, Rap1, Ral, and Rheb, have been implicated in axon initiation in hippocampal neurons (Fig. 2). The ectopic expression of CA-R-Ras induces multiple axons, whereas R-Ras depletion inhibits axon formation and these effects have been ascribed to R-Ras-dependent regulation of PI3kinase activity and the production of the signaling lipid $\mathrm{PIP}_{3}$ in the presumptive axon (Oinuma et al. 2007). A major target of $\mathrm{PIP}_{3}$ is the kinase Akt and one of its substrates, the kinase GSK-3, can be inactivated by phosphorylation. 


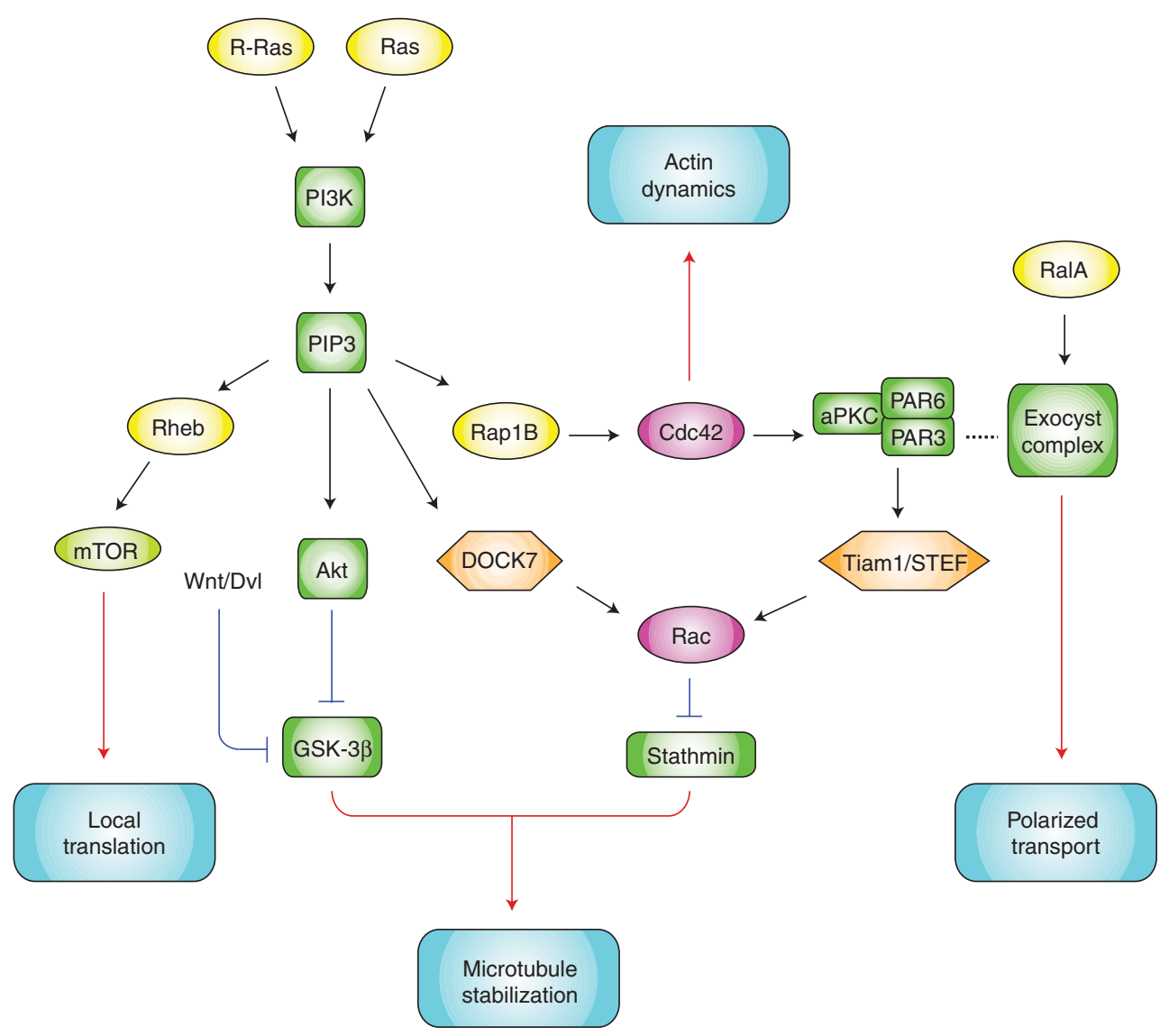

Figure 2. Rho and Ras GTPases in axon initiation. A simplified scheme showing some of the main axon initiation pathways involving Rho and Ras GTPases. Activation of Ras downstream of extracellular stimuli or adhesion to extracellular matrix leads to a phosphatidylinositol 3-kinase (PI3K)-mediated cascade of small GTPases regulating axon initiation, including the other Ras family members Rap1B and Rheb. Rap1B acts upstream of Cdc42 and the Par3/Par6/aPKC polarity complex, which can locally activate Rac through the Rac GEFs Tiam1 and STEF, and control not only actin dynamics, but also microtubule stability by inhibition of the microtubule destabilizing protein stathmin. The signaling lipid phosphatidylinositol-3, 4, 5-triphosphate $\left(\mathrm{PIP}_{3}\right)$ produced by PI3K also activates Rac via another GEF, DOCK7, and Rheb, which functions through its effector mammalian target of rapamycin (mTOR), a crucial regulator of translation. Localized inactivation of GSK-3 $\beta$ during axon growth may depend on Akt-dependent phosphorylation, but axon initiation seems to require an alternative mode of inhibition, possibly involving noncanonical Wnt/Dishevelled (Wnt/Dvl) signaling. Finally, RalA may participate in the polarized transport essential for axon initiation through its effector the exocyst complex, which could promote polarized trafficking of the PAR complex (dashed line). See text for a detailed explanation. (Yellow, Ras family GTPases; magenta, Rho family GTPases; orange, GEFs.)

There is strong evidence that the localized inactivation of GSK-3 at the tip of the presumptive axon is a key trigger for polarized microtubule growth (Zhou and Snider 2005; Kim et al. 2006; Arimura and Kaibuchi 2007; Ciani and Salinas 2007). RNAi-mediated depletion of Ras also blocks axon formation, and FRET imaging has revealed localized activation of Ras in the nascent axon (Fivaz et al. 2008). Interestingly, PI3-kinase leads to further activation of Ras, in a positive-feedback loop, as well as activation of Rap1B, which similarly localizes to the tip of the future axon in stage 2 neurons and is required for axon formation (Schwamborn and 
Puschel 2004). This same study reported that Rap1B acts upstream of Cdc42 (a Rho family member), suggesting a cascade of small GTPases acting at the tip of the presumptive axon. Yet another potential role for PI3-kinase is in the $\mathrm{Rheb} / \mathrm{mTOR}$ pathway, a central regulator of cell growth that also seems to influence neuronal polarization (Li et al. 2008b). Finally, the asymmetric transport of proteins to the axon and to the dendrites is essential for the establishment and maintenance of neuronal polarity. RalA interacts with the exocyst, an octameric protein complex promoting membrane delivery. The depletion of RalA, or of components of the exocyst complex in neurons causes axon loss, suggesting an important role for this GTPase in polarized trafficking to the axon (Lalli 2009).

One theme to emerge from these studies is the importance of the localized phosphorylation and inhibition of GSK-3 by Akt. However, neurons from a double knockin mouse in which the Akt-phosphorylation sites present on the two GSK-3 isoforms (Ser9 in GSK-3 $\beta$ - and Ser21 in GSK-3 $\alpha$ ) have been replaced by an alanine residue and show no defects in neuronal polarization (Gartner et al. 2006). This suggests that GSK-3 inhibition occurs through an alternative mechanism and there is evidence that this may involve noncanonical Wnt/Dishevelled signaling (Zhang et al. 2007).

A close interplay between the actin and microtubule cytoskeletons occurs at the tip of the presumptive axon, often visualized as growthcone enlargement, shortening of actin ribs, and subsequent penetration of microtubules into the central growth-cone region at the stage 2-3 transition. Indeed, localized microtubule stabilization (by taxol) or localized depolymerization of actin filaments (by cytochalasin) is sufficient to initiate axonal extension in a neurite (Witte and Bradke 2008). Rho family GTPases control the actin and microtubule cytoskeletons through specific effectors and play important roles in regulating neuronal polarization. A tight regulation of Cdc42 activity is required for axon specification, because neurons expressing CA-Cdc42 do not extend neurites, whereas cells transfected with a "fast cycling" Cdc42 mutant extend multiple axons
(Schwamborn and Puschel 2004). An important Cdc42 effector is the Par6/aPKC complex, which controls polarity in a variety of contexts, including morphogenesis, migration, and asymmetric cell division (Goldstein and Macara 2007). aPKC, in turn, regulates APC (the adenomatous polyposis coli tumor suppressor protein), which stabilizes microtubule plus ends at the tip of the presumptive axon (Shi et al. 2004). Cdc42 may also locally activate Rac through an interaction between Par3 (complexed with Par6) and two Rac GEFs, Tiam1 or Tiam2/STEF, both of which are reported to be essential for neuronal polarization (Nishimura et al. 2005). Because Rac can stimulate PI3-kinase, this may establish a positive-feedback loop between Cdc42 and Rac to reinforce neuronal polarization.

Rac regulates a parallel pathway that triggers microtubule growth in the nascent axon. Activation of the Rac GEF DOCK7 leads to Racmediated phosphorylation and inactivation of the microtubule destabilizing protein stathmin/Op18 in the nascent axon (Watabe-Uchida et al. 2006). One candidate for triggering localized activation of DOCK7 at the presumptive axon tip is the extracellular matrix protein laminin, which acts through the laminin receptor and $\mathrm{PIP}_{3}$ to recruit DOCK7 to the plasma membrane. The kinase responsible for stathmin phosphorylation is likely to be the Rac effector PAK (Daub et al. 2001). In hippocampal neurons, PAK is present in all neurites, but the activated ( phosphorylated) form is spatially restricted to the growing axon (Jacobs et al. 2007).

Rho appears to act antagonistically to $\mathrm{Cdc} 42 / \mathrm{Rac}$ and negatively regulates neurite extension through ROCK, a target kinase (Da Silva et al. 2003). DN-Rho does not alter axon number, but CA-Rho inhibits axon formation and induces round cells (Schwamborn and Puschel 2004). Inactivation of Rho/ROCK increases the amount of dephosphorylated profilin IIa, resulting in F-actin destabilization and sprout formation (Da Silva et al. 2003). Interestingly, the Rho/ROCK/PIIa cascade can be inactivated by plasma membrane ganglioside sialidase (PMGS), an enzymatic activity that localizes at the tip of the future axon in stage 2 
neurons and induces axon specification by enhancing TrkA activity (Da Silva et al. 2005).

\section{Insights from In Vivo Studies}

Loss-of-function studies of members of the Drosophila Rac family (DRac1, DRac2, and $\mathrm{Mtl}$ ) in both the visual system and mushroombody neurons have revealed specific roles in axon growth, guidance, and branching (HakedaSuzuki et al. 2002; Ng et al. 2002). Expression of CA-DRacl or DN-DRacl causes failure in axon, but not dendrite outgrowth, whereas mutants of DCdc42 affect general aspects of morphogenesis, including cell migration and dendrite/axonal outgrowth. A RhoA null mutation in mushroom-body neurons does not affect axon specification and growth, but causes dendrite overextension, whereas activated RhoA reduces dendritic complexity. These data support an important role for RhoA in dendritic, but not axonal morphogenesis (Lee et al. 2000). There are three Rac-like proteins in C. elegans: CED-10, Rac2/3, and MIG-2. They appear to have overlapping functions in several aspects of neuronal development. Interestingly, Rac double mutants display ectopic axons and branches, suggesting that Rac is involved in the suppression of superfluous axon and branches (Lundquist 2003). The analysis of a Cdc42 conditional knockout mouse, in which Cdc42 is depleted in late gestation in the cortex and hippocampus, revealed normal initial neurite sprouting, but a strong inhibition of axon formation (Garvalov et al. 2007). Further experiments using cultured Cdc42-null neurons suggested that this GTPase acts upstream of a local actin depolymerizing activity (perhaps cofilin), which is required for initial axon formation.

\section{GROWING AN AXON}

After the establishment of neuronal polarity, the axon may extend considerably depending on the type of neuron. Rho and Ras GTPases continue to play important roles during axon growth (Fig. 3).
Insights from Cell Culture Studies

In addition to their role in neuron polarization, the Rac GEFs Tiam1, and Tiam2/STEF are important players in axon extension (de Curtis 2008). The Rac/Cdc42 effector IQGAP3 is required for axon growth in hippocampal neurons-it localizes asymmetrically at the distal end of the axon, where it likely modulates both the actin and the microtubule cytoskeletons (Wang et al. 2007). In addition to IQGAP3, N-WASP may be an important Cdc42 effector during neurite extension. It promotes actin polymerization through the Arp2/3 complex and a dominant-negative version of N-WASP was reported to abolish neurite extension in hippocampal neurons (Banzai et al. 2000). However, in another report, a different dominantnegative version of N-WASP led to enhanced axon elongation in hippocampal neurons, suggesting that Arp2/3 antagonizes neurite extension (Strasser et al. 2004).

Rho and its downstream effector ROCK negatively regulate the early steps of axon outgrowth in cultured neurons (Govek et al. 2005). However, axon elongation in cerebellar granule neurons promoted by the neural chemokine stromal cell-derived factor (SDF) $-1 \alpha$ is mediated by Rho, though through a distinct signaling pathway involving another downstream effector, mDia (Arakawa et al. 2003). These experiments show the potential for confusion using a dominant-negative GTPase; thus, although a variety of upstream signals converge on Rho, they may lead to the activation of different signaling pathways.

Other members of the Rho family have also been linked to axon growth. The first GEF domain of Trio, which activates RhoG, is required for NGF-mediated neurite outgrowth in PC12 cells (Estrach et al. 2002). RhoG binds to Elmo, a scaffold for the Rac GEF Dock180 and thus may mediate Rac activation (Katoh and Negishi 2003). TC10, a close relative of Cdc42, was initially identified in neuronal cells as a gene that was dramatically re-expressed after axotomy of motor neurons in the hypoglossal nuclei (Tanabe et al. 2000). Low levels of TC10 are found in developing and adult brain, 


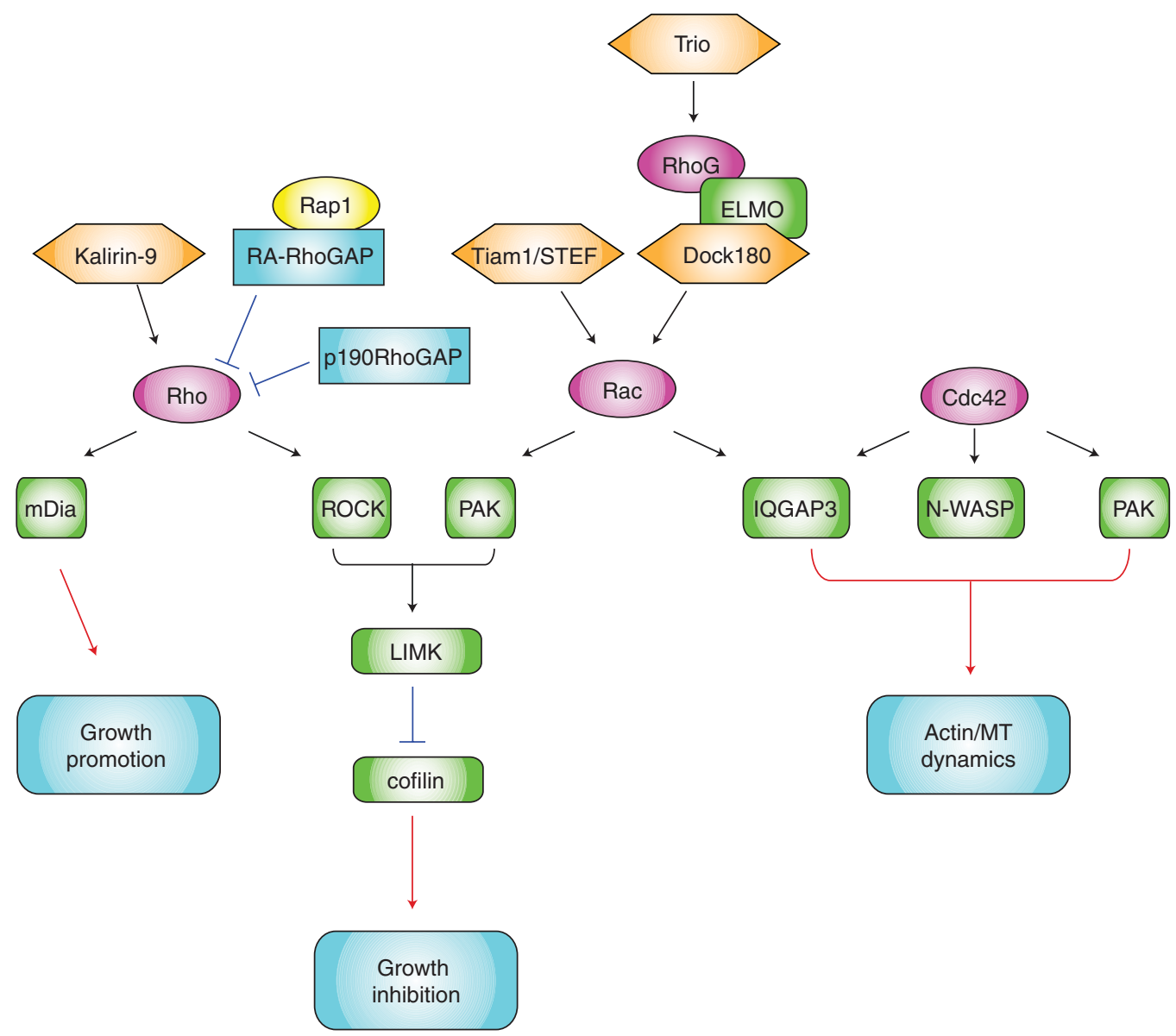

Figure 3. Rho GTPases in axon growth. Rho can either promote or inhibit axon extension depending on the type of effector (mDia or ROCK, respectively). The Rap1-activated RA-RhoGAP or p190RhoGAP (blue) inactivate Rho to promote axon growth. On the other hand, the Rho-specific GEF domain of Kalirin-9 activates Rho to promote axon growth. Both ROCK and PAK can inhibit the actin-depolymerizing factor cofilin through LIM kinase (LIMK). The balance of dephosphorylated (active) and phosphorylated (inactive) cofilin appears to be crucial for axonal extension. Several GEFs (orange) like Tiam1, STEF, and Dock180 may act upstream of Rac to regulate actin and microtubule dynamics. Cdc42 can also control the actin and microtubule cytoskeletons during axon growth via some of its effectors like IQGAP3, PAK, and N-WASP. See text for details.

but its up-regulation after nerve injury suggests a role in neurite elongation. Indeed, TC10 overexpression in cultured dorsal root ganglia (DRG) promotes axon extension.

Less is known about the contribution of the Ras family to axon elongation. Ras is involved in NGF-mediated axon growth, but is also required for neuronal survival, thus complicating any molecular analysis. In embryonic DRG neurons, the Ras effector Raf promotes axon elongation, whereas another Ras effector Akt causes an increase in axon caliber and branching (Markus et al. 2002). The Rit GTPase is widely expressed in the developing and adult nervous system, and has recently emerged as a convergence point for multiple signaling pathways involving NGF and BMP and axonal growth (Lein et al. 2007). Interestingly, Rit stimulates ERK MAP kinase signaling and interacts with the polarity protein Par6, which could function to spatially localize this GTPase at the tip of the growing axon (Rudolph et al. 2007). 
Insights from In Vivo Studies

In Drosophila sensory neurons, expression of either CA-DRac or DN-DRac causes axonal outgrowth arrest without affecting dendrites, whereas in motor neurons, an inactive DRacl mutation disrupts axon trajectory, without inhibiting their extension (Luo et al. 1994; Kaufmann et al. 1998). In giant fibers, overexpression of wild-type DRacl affects axonal morphology, CA-DRac1 inhibits neurite outgrowth, and DN-DRacl causes axonal ectopic branching (Allen et al. 2000). It is not so clear how to interpret these results; notwithstanding the potential problems associated with expressing constitutively activated GTPases, it does seem that the role of Rac differs in different neuronal types. Partially redundant functions of DRac1, DRac2, and Mtl in axon outgrowth have been shown in two distinct contexts: the visual system and mushroom-body neurons. Furthermore, varying the level of Rac activation results in different outcomes, such that progressive loss of activity leads first to defects in branching, then guidance, and finally outgrowth ( $\mathrm{Ng}$ et al. 2002). This suggests that Rac may activate different downstream pathways under these different conditions. Interestingly, CRIB motif-containing effectors (such as PAK) seem not to be required for axon outgrowth (Kim et al. 2003). To complicate matters further, Rac may have a dual role: inhibiting axon growth through Trio/Rac/PAK/LIMK and cofilin phosphorylation, but promoting growth in a PAK-independent fashion downstream of another Rac GEF, still life (STEF) (Ng and Luo 2004). Activation of RhoA through the GEF Pebble results in axon growth inhibition through ROCK, which inactivates cofilin via LIMK-mediated phosphorylation. Cofilin phosphorylation and dephosphorylation therefore represent important regulatory steps in axonal growth.

Drosophila RacGAP50C (Tum) is important during cytokinesis, but in the post-mitotic neurons of the mushroom body, RNAi-mediated depletion leads to axon overextension (Goldstein et al. 2005). Its axon growth limiting function is lost if the GAP domain, which likely acts on Rac, is mutated (Canman et al. 2008). Through an interaction with the kinesin Pavarotti (pav), Tum may help spatially regulate Rac activity during axon growth. Mosaic analysis in the Drosophila mushroom body revealed a surprisingly selective function for RhoA in dendritic, but not axonal morphogenesis, and neurons lacking RhoA overextend their dendrites, but display normal axon projections (Lee et al. 2000). In C. elegans, Rac mutants display premature axon growth arrest (Lundquist 2003). RhoA RNAi causes embryonic lethality; however, studies with CA-Rho and DN-Rho suggest an inhibitory role in neurite outgrowth of chemosensory neurons (Zallen et al. 2000).

The expression of CA-Racl in mouse Purkinje neurons inhibits axonal outgrowth and alters the number and morphology of dendritic spines, without blocking dendritic growth or branching (Luo et al. 1996). The negative regulator of Rho, p190 RhoGAP, is a major Src substrate in the brain and is involved in axon growth, guidance, and defasciculation. Extracellular matrix components, such as laminin, enhance p190-mediated neurite outgrowth, whereas mice lacking functional p190 RhoGAP have substantial defects in axon extension (Brouns et al. 2001). In contrast to the Drosophila studies, some of the CRIB motif-containing effectors appear to be involved in axon growth in mice. Indeed, knockout of the Cdc42 effector PAK4 impairs axon extension, besides causing a variety of other neuronal development defects (Qu et al. 2003). A tight regulation of PAK3 expression levels by the homeobox transcription factors Dlx1/2 seems to be crucial in restraining neurite growth and promoting tangential migration (Cobos et al. 2007).

\section{GUIDING THE AXON}

Axon guidance is directed by numerous soluble, matrix and cell-bound ligands acting through distinct receptors at the tip of the axon-the growth cone. Localized changes in filamentous actin in the growth cone direct microtubule dynamics and thereby the direction of axonal elongation. Given the importance of Rho 
GTPases in regulating the actin cytoskeleton, they have been a major focus in the analysis of signaling by guidance cues. Rho and ROCK often appear to work antagonistically to Rac/ Cdc42; the former associated with repulsive cues and growth-cone collapse and the latter with attractive cues and forward protrusion. However, closer examination of the signaling pathways reveals a far more complex story. We also refer the reader to the article by Bashaw and Klein for more extensive discussion on signaling downstream of guidance receptors (Bashaw and Klein 2010).

In Drosophila, gain-of-function and lossof-function Rac mutations have distinct effects on motor axon pathways, pointing to a role for Rac in executing specific guidance decisions (Luo et al. 1994). Similarly, Rac activation is required during neuromuscular development for directional specificity and target recognition, whereas Cdc42 is necessary for motor-axon extension (Kaufmann et al. 1998). A targeted knockout approach for Racl in mouse ventral telencephalic neurons revealed a requirement in the formation of midline commissures, as well as proper fasciculation and targeting of thalamocortical and corticothalamic axons (Chen et al. 2007). The ability of Rac to affect specific guidance decisions is further shown by the fact that commissural axons of cortex-restricted Rac1 knockout mice still display potent extension, yet fail to cross the midline (Kassai et al. 2008). Misregulation of Rho activity has a substantial impact on axonal guidance. p190RhoGAP knockout mice, for example, display clear guidance defects in the axonal projections of the posterior limb of the anterior commissure (Brouns et al. 2001). The abundance and broad distribution of p190RhoGAP in the nervous system makes this GAP a crucial mediator linking diverse extracellular guidance cues with Rho-dependent cytoskeletal rearrangements.

Some of the upstream activators and downstream effectors that participate in Rac pathways have been identified. Single mutants of any of the three Rac-like genes in C. elegans (ced-10, mig-2, and rac-2) lead to subtle phenotypes, but double mutants cause severe defects in axon pathfinding, as well as outgrowth. The
Rac GEF UNC-73 (Trio) acts in all Rac-dependent pathfinding pathways, whereas another GEF, CED-5 (DOCK180), acts with MIG-2, but not with CED-10 (Lundquist et al. 2001). Trio was initially characterized in Drosophila as an essential regulator of PAK during photoreceptor axon guidance (Bateman et al. 2000). The axon patterning defects observed in Trio mosaics are remarkably similar to those seen in both PAK and Dock mutants, suggesting that Trio/Dock/PAK act together in a single signaling pathway regulating axon guidance (Newsome et al. 2000).

\section{Semaphorins}

Semaphorins (collapsins) are a family of secreted or membrane-bound proteins that promote either attractive or repulsive guidance through their interaction with the plexin/neuropilin receptor family (Kruger et al. 2005). Growth-cone collapse induced by Sema3A, which acts through the neuropilin1/plexinA1 receptor complex, depends on Rac and Rho activity (Jin and Strittmatter 1997; Kuhn et al. 1999; Vastrik et al. 1999; Turner et al. 2004) (Fig. 4A). Rac.GTP interacts directly with plexin $\mathrm{A}$ and plexinB receptors, a highly unusual situation for a small GTPase and a transmembrane receptor. Some have suggested that this represents sequestration (essentially inactivation) of $\mathrm{Rac}$ (Hu et al. 2001; Vikis et al. 2002). However, collapse induced by a ligandindependent version of plexinA1 does not require Rac, which would be consistent with the receptor being a downstream effector of Rac (Turner et al. 2004). One idea is that Rac induces a conformational change in the cytoplasmic tail of the receptor (i.e., in a similar way to other targets of Rho GTPases), though an alternative possibility is that Rac promotes receptor endocytosis, which is required for Sema3A-induced growth-cone collapse (Jurney et al. 2002).

Sema3A leads to the activation of Rho and ROCK, and attenuates actin polymerization, while promoting intra-axonal F-actin bundling and myosin II-mediated force generation (Gallo 2006). In hippocampal neurons, 


\section{A}

\section{PlexinA1}

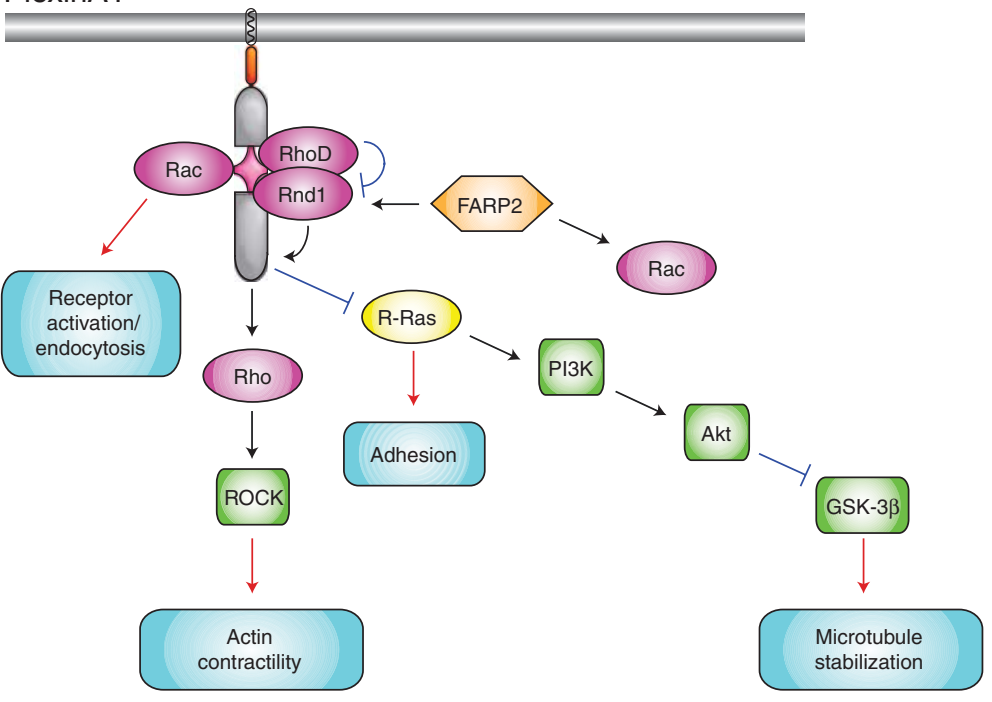

B

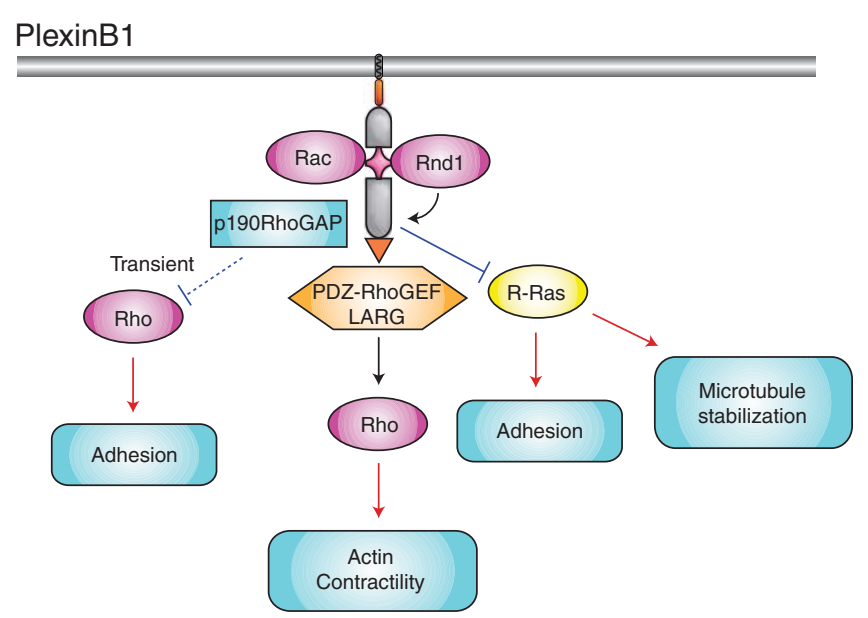

Figure 4. Rho and Ras GTPases in Semaphorin signaling. (A) Signaling downstream of plexinA1 receptors involves up-regulation of Rho activity, leading to an increase in ROCK-mediated actin contractility. In addition, direct binding of Rac.GTP to the GTPase-binding region of plexin (pink rhombus) may induce a conformational change in the plexin cytoplasmic tail and enhance receptor endocytosis. Sema3A-induced dissociation of the Rac GEF FARP2 from the plexinA1/neuropilin complex promotes the recruitment of Rnd1 to plexinA1. The Rnd1/plexinA1 interaction opens the two R-Ras GAP domains of plexinA1 (gray), thus leading to R-Ras inactivation. This event may facilitate growth-cone collapse by inhibiting integrin-mediated adhesion and promoting microtubule destabilization (through a decrease in PI3K/Akt and a subsequent increase in GSK-3 activities). Only the intracellular domain of the plexin receptor is shown and interactions with co-receptors are not shown. (B) Rho activity downstream of plexinB1 undergoes transient down-regulation via p190RhoGAP, possibly to mediate inhibition of integrin function. The PDZ domain-binding motif exclusively present in the plexinB receptor subfamily (orange triangle) interacts with the Rho GEFs PDZ-RhoGEF and LARG in a Sema-dependent fashion, thereby causing Rho activation and growth-cone collapse. Similar to plexinA1, the association with Rnd1 is required to enable the R-Ras GAP activity of plexinB1. Only the intracellular domain of the plexin receptor is shown and interactions with co-receptors are not shown. 
Sema4D/plexin-B1 activates Rho through the GEF, LARG (Swiercz et al. 2002) (Fig. 4B). The relationship between plexin signaling and Rho may be more complex, because a transient down-regulation of Rho by p190RhoGAP appears to be necessary for growth-cone collapse (Barberis et al. 2005). A further twist to this story stems from the observation that Sema3A induces intra-axonal translation of RhoA mRNA, which, through an axonal $3^{\prime}$ UTR targeting element, is localized in developing axons and growth cones (Wu et al. 2005). This local translation appears to be necessary and sufficient for Sema3A-induced growth-cone collapse.

The atypical Rho family members, Rnd1/2/ 3 , have also been linked to plexin signaling. Rnd1 promotes an R-Ras GAP activity encoded within the cytoplasmic tail of plexinB1 (Oinuma et al. 2004a; Oinuma et al. 2004b). The interaction of Rnd1 with plexinA1 is required for Sema3A/plexinA1-mediated repulsion, although in this context, yet another small GTPase, RhoD, has been reported to antagonize Rnd1 signaling and prevent Sema3A-induced repulsion (Zanata et al. 2002). The R-Ras GAP-related domain is well conserved among different plexin subfamilies and is likely to be a significant feature of all semaphorin signaling. PlexinC1 and plexinD1 have R-Ras GAP activity, though in the former case this appears to be constitutive, whereas in the latter, it requires Rnd2 (Uesugi et al. 2009). The role of R-Ras in growth-cone guidance, however, is not clear. It regulates integrin-mediated cell adhesion, and so down-regulation could reduce cell adhesiveness, but in addition can regulate PI3-kinase and therefore potentially modify microtubule dynamics via Akt/GSK-3 (Ito et al. 2006). Interestingly, Sema3A promotes the dissociation of the Rac GEF FARP2 from plexinA1/ neuropilin-1, which leads not only to Rac activation, but also to the recruitment of Rnd 1 to plexinA1, thus triggering its R-Ras GAP activity (Toyofuku et al. 2005).

\section{Ephrins}

Ephrins are transmembrane or glycosylphosphatidylinositol-anchored ligands recognized by the Eph family of receptor tyrosine kinases.
They act as repulsive cues through activation of Rho and ROCK in the growth cone (Wahl et al. 2000; Reber et al. 2007) (Fig. 5A). The GEF ephexin has been reported to be involved in Rho activation downstream of EphA4 (Shamah et al. 2001). However, ephexin-1 knockout mice are apparently normal, raising the possibility of redundancy within the very large family (82) of mammalian Rho family GEFs (Schmidt and Hall 2002; Sahin et al. 2005). An alternative mechanism to regulate Rho GTPases is through GAPs. EphrinB3 acting through EphA4 contributes to the formation of two major motor circuits: the corticospinal tract (CST) and the spinal neuronal circuit controlling locomotion (central pattern generator). The signaling pathway involves activation of the Rac GAP, $\alpha$-chimerin, and the loss of $\alpha$-chimerin in mice (leading presumably to hyperactivation of Rac) causes a failure in CST axons from stopping at the midline (Iwasato et al. 2007). Similar conclusions were reached using cultured hippocampal neurons, where EphrinA-induced growth-cone collapse was associated with tyrosine phosphorylation of $\alpha 2$-chimerin and inhibition of Rac/PAK signaling (Shi et al. 2007).

On the face of it, inhibition of Rac makes sense in the context of repulsive cues. Surprisingly, however, one study reported that although Rac activity decreases transiently in neurons treated with ephrin-A2, growth-cone collapse correlates with the resumption of Rac activity (Jurney et al. 2002). The authors concluded that this is due to Rac-mediated endocytosis of the growth-cone plasma membrane. Indeed, Eph triggered Vav2 (a Cdc42/Rac GEF) activation leads to endocytosis of the ligand/receptor complex and contributes to a repulsive phenotype (Cowan et al. 2005).

Eph receptors activate Ras family GTPases, but their contributions are less clear. EphB2 interacts with a GEF, SHEP1, which can activate both R-Ras and Rap1A, whereas EphA4 interacts with a Rap1 GAP, SPAR (Dodelet et al. 1999; Richter et al. 2007). SPAR-mediated inactivation of Rap1 is necessary for ephrinAdependent growth-cone collapse in hippocampal neurons. Both R-Ras and Rap1 have been shown to affect integrin activity, but whether 
A
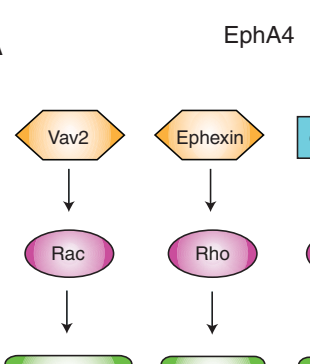

Endocytosis
EphA4

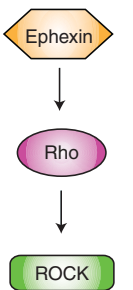

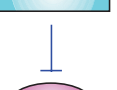
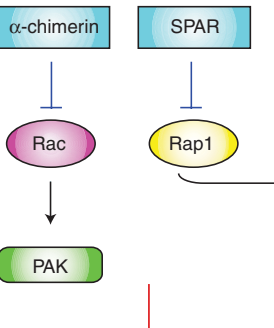

p120RasGAP

EphB2

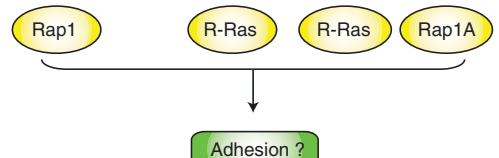

$\downarrow$

dhesion?

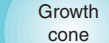

collapse

B

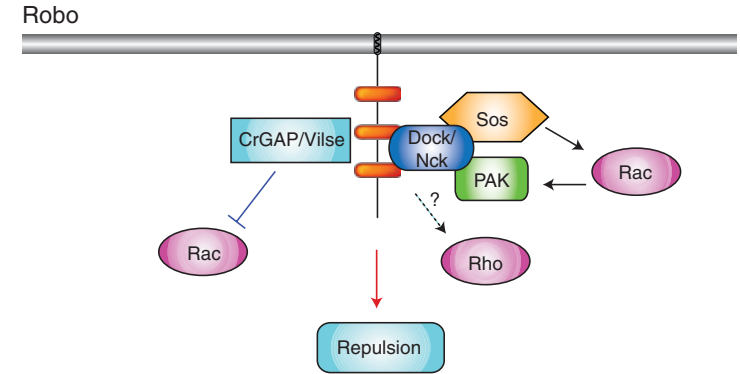

C

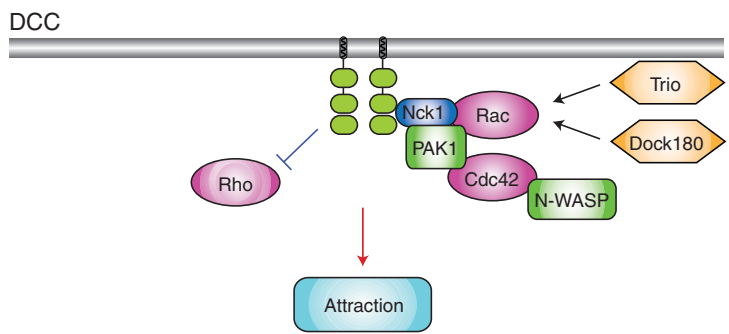

Figure 5. Rho and Ras GTPases in Ephrin/Slit/Netrin signaling. (A) Schematic of the GEFs and GAPs involved in EphA4 (left) or EphB2 (right) signaling. Inhibition of Rac/PAK cascade (by the Rac GAP $\alpha$-chimerin) may function together with ephexin-mediated Rho activation in controlling the cytoskeletal rearrangements leading to growth-cone collapse. However, Rac activation (by Vav2) can also contribute to collapse by stimulating endocytosis of the Ephrin/Eph complex. A tight regulation of R-Ras and Rap1 through GAPs (SPAR, p120RasGAP) and GEFs (like SHEP1) seems to be needed downstream of Eph signaling, possibly for the control of matrix adhesion. (B) Rac activity appears to be tightly regulated downstream of Slit through the GEF Sos and the GAP CrGAP/Vilse. Slit stimulation recruits the adaptor protein Dreadlocks (Drosophila Dock/vertebrate Nck) and subsequently PAK to Robo conserved cytoplasmic (CC) sequences (orange). The Robo/Dock complex interacts with Sos, mediating Slit-dependent Rac activation. The role of Rho in Slit/ Robo signaling remains unclear and may depend on the neuronal context. $(C)$ DCC homodimers promote growth-cone attraction through Rac, Cdc42, and PAK activation. On Netrin-1 binding, the adaptor Nck (which constitutively interacts with DCC), active Rac, Cdc42, Pak1, and N-WASP are recruited into a complex with the intracellular domain of DCC, triggering reorganization of the growth-cone actin cytoskeleton. The GEFs DOCK180 and Trio appear to be involved in netrin-1-dependent Rac activation. DCC may also down-regulate Rho and ROCK; however, the signaling mechanisms leading to the modulation of Rho activity downstream of netrin are still unclear, and they are likely to include cross talk with other GTPases. Only the intracellular domains of Robo and the DCC homodimer are shown in $(B)$ and $(C)$, respectively. 
their role in growth-cone guidance relates to matrix adhesion is not known.

\section{Other Guidance Cues}

The Slit family of repulsive guidance factors are present at the midline of the nervous system and act through Roundabout (Robo) receptors (Guan and Rao 2003). Slit stimulation in Drosophila leads to Rac activation and recruitment of the Nck adaptor protein and PAK to the Robo receptor (Fig. 5B) (Fan et al. 2003). Dosesensitive and loss-of-function genetic analyses reveal that limiting Nck, PAK, or Rac activities disrupts Robo repulsion. Subsequent studies have suggested that the dual specificity Ras/ Rac GEF, Sos, is responsible for Rac activation downstream of Slit (Yang and Bashaw 2006). These findings show yet again a role for Rac in mediating repulsive cues. Robo also interacts with the Rac/Cdc42 GAP, CrGAP/Vilse, and both RNAi and gain-of-function experiments indicate that regulation of Rac activity by both GEFs and GAPs is necessary for proper Robo signaling ( $\mathrm{Hu}$ et al. 2005). Consistent with an active role for Rho in Slit-dependent repulsion, DN-DRho enhances and CA-DRho suppress midline-crossing defects caused by homozygous loss of Sos in Drosophila CNS (Fritz and VanBerkum 2002). In contrast to this, overexpression of the Rho GEF GEF64C results in too many axons crossing the midline, similar to the Robo loss-of-function phenotype. In this context, however, it appears that Rho (at least when activated by this specific GEF) interferes with the repulsive cues downstream of Robo (Bashaw et al. 2001).

Netrins, acting through the DCC family of receptors, promote growth-cone attraction through DCC homodimers or repulsion through DCC/ UNC-5 heterodimers (Moore et al. 2007). Netrin-1-induced neurite outgrowth in embryonic rat spinal commissural axons requires both Rac and Cdc42 (Shekarabi and Kennedy 2002). Down-regulation of Rho or ROCK, on the other hand, stimulates the DCC-induced neurite outgrowth (Li et al. 2002b). Nck constitutively interacts with DCC in embryonic spinal commissural neurons through its two $\mathrm{SH} 3$ domains and, in the presence of netrin-1, mediates Rac activation (Li et al. 2002a) (Fig. 5C). Netrin-1 also promotes activation of $\mathrm{Cdc} 42$ and PAK, which together with N-WASP are recruited into a complex with the intracellular domain of DCC (Shekarabi et al. 2005). Recent studies have identified two distinct Rac GEFs, Trio and Dock180, in the netrin-1 attractive pathway. Netrin-1- and DCC-dependent neuronal projections in the developing spinal cord and in the brain (such as the anterior commissure, internal capsule, and the corpus callosum) are impaired in Trio-deficient mouse embryos (Briancon-Marjollet et al. 2008). In addition, Dock180 depletion attenuates netrin-stimulated axon growth in vitro as well as projections of commissural axons to the floor plate in chick embryos (Li et al. 2008a).

Inhibitory molecules associated with myelin and oligodendrocytes include myelin-associated glycoprotein (MAG), Nogo-A, chondroitin sulfate proteoglycans (CSPGs), and oligodendrocyte myelin glycoprotein (OMgp) (Govek et al. 2005). Although traditionally studied for their presence in the glial scar, their expression in the CNS and PNS during neuronal development indicates a likely role in axon guidance. The Nogo receptor (NgR), a glycosyl-phosphatidyl-inositol (GPI)-anchored protein mediates the inhibitory effects of Nogo-A, MAG, and OMgp (Schwab 2004). Active domains of Nogo plus the extracellular domain of MAG activate Rho and decrease Rac activity, and accordingly their inhibitory effect on neurite outgrowth can be abolished by the Rho inhibitor C3 exoenzyme, or by the ROCK inhibitor Y-27632 (Govek et al. 2005). The low-affinity neurotrophin receptor $\mathrm{p} 75^{\mathrm{NTR}}$ acts as an NgR co-receptor (Wang et al. 2002) and leads to Rho activation by promoting its dissociation from a RhoGDI complex (Yamashita and Tohyama 2003). The GEF Trio can mediate Rho activation in response to MAG, triggering a Rho/ ROCK/LIMK and cofilin phosphorylation pathway to inhibit neurite outgrowth (Harrington et al. 2008). ROCK also phosphorylates and inactivates CRMP-2 (a promoter of microtubule assembly) in postnatal cerebellar neurons and overexpression of a nonphosphorylatable 
form of CRMP-2 prevents the MAG inhibitory effect (Mimura et al. 2006).

Overall, it is hard to extract clear conclusions concerning the relative contributions of Rho GTPases to axon guidance. Several explanations may account for this, including the use of constitutively active and dominant-negative GTPases, the use of growth-cone collapse assays as a surrogate for guidance, and the potential variations between different neuronal types. Furthermore, because each of the Rho GTPases has maybe ten to twenty distinct downstream target proteins, this too is likely to account for some of the apparent confusion.

\section{BRANCHING THE AXON}

Axon branching provides a single neuron with the ability to establish synaptic contacts with multiple targets and is crucial for the assembly of highly interconnected networks. There are several branching modes: terminal axon branching through growth-cone bifurcation, delayed branching where a branch springs from an unstable membrane region left behind by a previous growth cone, and interstitial branching where a branch emerges from the axon shaft at sites distant from the growth cone, usually in an orthogonal orientation (Acebes and Ferrus 2000). Axonal branching is characterized by bundled microtubules splaying apart and "invading" local actin-rich filopodial-like structures on the axon shaft (Kalil et al. 2000).

\section{Insights from Cell Culture Studies}

The Rac isoform Rac3, but not Rac1, promotes neuritogenesis and branching when overexpressed in cultured chick retinal neurons (Albertinazzi et al. 1998; Albertinazzi et al. 2003). Notably, this activity maps to the carboxy-terminus of Rac3, the only region of the protein that differs significantly from Rac1. However, Rac3 null mice develop normally, suggesting potential redundancy in vivo (Corbetta et al. 2005). Because branching relies on filopodial extension, Cdc42-mediated actin polymerization through $\mathrm{N}-\mathrm{WASP} / \mathrm{Arp} 2 / 3$ might be expected to be important. However, depletion of N-WASP or Arp2/3 activity in rodent hippocampal neurons enhances axon branching (Strasser et al. 2004; Kakimoto et al. 2006). Perhaps mDia, which promotes actin polymerization and affects microtubule dynamics, or IRSp53, which has been linked to filopodia formation and spine morphogenesis, might be better candidates for Cdc42 targets involved in branching (Fukata et al. 2003; Scita et al. 2008). The role of Rho in branching is complex. Rho facilitates branching in cultured hippocampal neuron axons and activity-dependent branching of upper cortical layer axons in slice cultures (Ahnert-Hilger et al. 2004; Ohnami et al. 2008). On the other hand, Rho is required for TNF-induced inhibition of branching in hippocampal neurons (Neumann et al. 2002). An explanation for these apparent discrepancies might lie in the nature of the Rhodependent signals elicited in the two contexts.

RalA and RalB promote neurite branching in cortical and SCG neurons through distinct effectors, the exocyst complex and phospholipase $\mathrm{D}$, respectively. Moreover, they both enhance phosphorylation of GAP-43, a neuronal protein with sprout-promoting activity involved in terminal arborization at innervation sites (Lalli and Hall 2005). In neurons, Ral proteins are activated by laminin, suggesting a role for these GTPases in mediating branching downstream of integrin signaling. The in vivo function of Ral in axon branching and the upstream activators involved remain to be investigated.

\section{Insights from In Vivo Studies}

In Drosophila mushroom-body neurons, loss of one allele of Racl causes defects in branching, but does not affect axon growth or guidance. Moreover, Rac mutants unable to interact with CRIB motif-containing effectors can rescue guidance (seen after inactivation of both alleles encoding Racl) and growth (seen after inactivation of all three genes encoding Rac-like GTPases), but not branching, suggesting that these play an active role in this process $(\mathrm{Ng}$ et al. 2002). The importance of Rac regulation in axon branching is further supported by studies in C. elegans, where neuron-specific 
expression of a CA-Rac results in extensive axon branching and formation of ectopic lamellipodia and filopodia (Lundquist 2003). In the Drosophila giant fiber system, on the other hand, DN-Rac increases axon branching, suggesting a negative role for Rac (Allen et al. 2000). These contrary indications linking Rac to branching are not easy to reconcile, other than by invoking differences in neuron type. Inhibiting either Rac or Cdc42 in chick RGC axons impaired the birth and growth of collateral branches of the retinotectal map. The interstitial axonal branching observed in this system is tightly controlled by repellent tectal cues activating Rho/ROCK and promoting branch retraction (Thies and Davenport 2003). p190RhoGAP was identified as a key modulator of axonal branching in the Drosophila mushroom-body system and loss of this protein leads to axon branch retraction; a phenotype that can be mimicked by activated Rho or ROCK and involves activation of myosin II (Billuart et al. 2001). Interestingly, loss of Rho in mushroom-body neurons did not cause detectable phenotypes.

The deletion of the RasGAP neurofibromin (NF1) in adult mouse DRG proprioceptive sensory neurons results not only in enhanced intrinsic axonal outgrowth and branching, but also enhanced capacity for collateral sprouting in response to spinal cord injury (Romero et al. 2007). Sensory neurons respond to neurotrophins, such as NGF, primarily through activation of Raf/MEK/ERK and PI3-kinase/ Akt/GSK-3 $\beta$. Although the former is generally associated with survival, the latter seems to be linked to neurite growth (Zhou et al. 2004). In sensory neurons, activated Raf led to axon extension similar to NGF, whereas active Akt specifically increased axon branching and caliber (Markus et al. 2002). How Akt acts is not known, but PAK or GSK-3 $\beta$ could be involved. Local inactivation of GSK-3 $\beta$ at the distal axon leads to accumulation of dephosphorylated APC at microtubule plus ends and promotion of microtubule assembly, which is necessary for NGF-induced axon growth. In contrast, a more global inactivation of GSK-3 $\beta$ causes increased APC accumulation along the axon shaft, promoting the appearance of microtubule protrusions and branches along the axon (Zhou et al. 2004). Inactivation of GSK-3 $\beta$ could also decrease phosphorylation of CRMP-2, thus enhancing its ability to bind tubulin and promote microtubule assembly, and overexpression of CRMP-2 has been shown to promote axon growth and branching (Fukata et al. 2002).

\section{CONCLUDING REMARKS}

A wide range of studies carried out in tissue culture and in animals has identified Rho and Ras GTPases as critical regulators of axon morphogenesis. Early indications that axon growth and guidance could simply be explained by antagonistic effects of Rac and Rho on the actin cytoskeleton have given way to a more complex scenario, in which multiple small GTPases each act locally to promote discrete downstream signaling events, sometimes antagonistic, sometimes synergistic. Deciphering the individual biochemical processes that operate in highly localized regions of the developing axon represents a considerable future challenge, even in cell culture, and will likely depend on the development of sophisticated imaging tools capable of monitoring signal transduction pathways in living cells.

\section{ACKNOWLEDGMENTS}

We apologize to those authors whose work could not be cited due to space limitation. G.L. is funded by a King's College New Investigator Fellowship.

\section{REFERENCES}

Acebes A, Ferrus A. 2000. Cellular and molecular features of axon collaterals and dendrites. Trends Neurosci 23: 557-565.

Ahnert-Hilger G, Holtje M, Grosse G, Pickert G, Mucke C, Nixdorf-Bergweiler B, Boquet P, Hofmann F, Just I. 2004. Differential effects of Rho GTPases on axonal and dendritic development in hippocampal neurones. J Neurochem 90: 9-18.

Albertinazzi C, Gilardelli D, Paris S, Longhi R, de Curtis I. 1998. Overexpression of a neural-specific rho family GTPase, cRac1B, selectively induces enhanced neuritogenesis and neurite branching in primary neurons. $J$ Cell Biol 142: 815-825. 
Albertinazzi C, Za L, Paris S, de Curtis I. 2003. ADP-ribosylation factor 6 and a functional PIX/p95-APP1 complex are required for Rac1B-mediated neurite outgrowth. Mol Biol Cell 14: 1295-1307.

Allen MJ, Shan X, Murphey RK. 2000. A role for Drosophila Dracl in neurite outgrowth and synaptogenesis in the giant fiber system. Mol Cell Neurosci 16: 754-765.

Arakawa Y, Bito H, Furuyashiki T, Tsuji T, Takemoto-Kimura S, Kimura K, Nozaki K, Hashimoto N, Narumiya S. 2003. Control of axon elongation via an SDF- $1 \alpha /$ Rho/mDia pathway in cultured cerebellar granule neurons. $J$ Cell Biol 161: 381-391.

Arimura N, Kaibuchi K. 2007. Neuronal polarity: from extracellular signals to intracellular mechanisms. Nat Rev Neurosci 8: 194-205.

Banzai Y, Miki H, Yamaguchi H, Takenawa T. 2000. Essential role of neural Wiskott-Aldrich syndrome protein in neurite extension in $\mathrm{PC} 12$ cells and rat hippocampal primary culture cells. J Biol Chem 275: 11987-11992.

Barberis D, Casazza A, Sordella R, Corso S, Artigiani S, Settleman J, Comoglio PM, Tamagnone L. 2005. p190 Rho-GTPase activating protein associates with plexins and it is required for semaphorin signalling. $J$ Cell Sci 118: $4689-4700$.

Bashaw GJ, Klein R. 2010. Signaling from axon guidance receptors. Cold Spring Harb Perspect Biol 2: a001941.

Bashaw GJ, Hu H, Nobes CD, Goodman CS. 2001. A novel Dbl family RhoGEF promotes Rho-dependent axon attraction to the central nervous system midline in Drosophila and overcomes Robo repulsion. J Cell Biol 155: 1117-1122.

Bateman J, Shu H, Van Vactor D. 2000. The guanine nucleotide exchange factor trio mediates axonal development in the Drosophila embryo. Neuron 26: 93-106.

Billuart P, Winter CG, Maresh A, Zhao X, Luo L. 2001. Regulating axon branch stability: The role of p190 RhoGAP in repressing a retraction signaling pathway. Cell 107: 195-207.

Briancon-Marjollet A, Ghogha A, Nawabi H, Triki I, Auziol C, Fromont S, Piche C, Enslen H, Chebli K, Cloutier JF, et al. 2008. Trio mediates netrin-1-induced Racl activation in axon outgrowth and guidance. Mol Cell Biol 28: 2314-2323.

Brouns MR, Matheson SF, Settleman J. 2001. p190 RhoGAP is the principal Src substrate in brain and regulates axon outgrowth, guidance and fasciculation. Nat Cell Biol 3: 361-367.

Calderon de Anda F, Gartner A, Tsai LH, Dotti CG. 2008. Pyramidal neuron polarity axis is defined at the bipolar stage. J Cell Sci 121: 178-185.

Canman JC, Lewellyn L, Laband K, Smerdon SJ, Desai A, Bowerman B, Oegema K. 2008. Inhibition of Rac by the GAP activity of centralspindlin is essential for cytokinesis. Science 322: 1543-1546.

Chalasani SH, Sabelko KA, Sunshine MJ, Littman DR, Raper JA. 2003. A chemokine, SDF-1, reduces the effectiveness of multiple axonal repellents and is required for normal axon pathfinding. J Neurosci 23: 1360-1371.

Chalasani SH, Sabol A, Xu H, Gyda MA, Rasband K, Granato M, Chien CB, Raper JA. 2007. Stromal cell-derived factor-1 antagonizes slit/robo signaling in vivo. J Neurosci 27: 973-980.

Chen L, Liao G, Waclaw RR, Burns KA, Linquist D, Campbell K, Zheng Y, Kuan CY. 2007. Racl controls the formation of midline commissures and the competency of tangential migration in ventral telencephalic neurons. $J$ Neurosci 27: 3884-3893.

Ciani L, Salinas PC. 2007. c-Jun N-terminal kinase (JNK) cooperates with Gsk $3 \beta$ to regulate Dishevelled-mediated microtubule stability. BMC Cell Biol 8: 27.

Cobos I, Borello U, Rubenstein JL. 2007. Dlx transcription factors promote migration through repression of axon and dendrite growth. Neuron 54: 873-888.

Colicelli J. 2004. Human RAS superfamily proteins and related GTPases. Sci STKE 2004: RE13.

Corbetta S, Gualdoni S, Albertinazzi C, Paris S, Croci L, Consalez GG, de Curtis I. 2005. Generation and characterization of Rac3 knockout mice. Mol Cell Biol 25: 5763-5776.

Cowan CW, Shao YR, Sahin M, Shamah SM, Lin MZ, Greer PL, Gao S, Griffith EC, Brugge JS, Greenberg ME. 2005. Vav family GEFs link activated Ephs to endocytosis and axon guidance. Neuron 46: 205-217.

Da Silva JS, Hasegawa T, Miyagi T, Dotti CG, Abad-Rodriguez J. 2005. Asymmetric membrane ganglioside sialidase activity specifies axonal fate. Nat Neurosci 8: 606-615.

Da Silva JS, Medina M, Zuliani C, Di Nardo A, Witke W, Dotti CG. 2003. RhoA/ROCK regulation of neuritogenesis via profilin IIa-mediated control of actin stability. J Cell Biol 162: 1267-1279.

Daub H, Gevaert K, Vandekerckhove J, Sobel A, Hall A. 2001. Rac/Cdc42 and p65PAK regulate the microtubuledestabilizing protein stathmin through phosphorylation at serine 16. J Biol Chem 276: 1677-1680.

de Curtis I. 2008. Functions of Rac GTPases during neuronal development. Dev Neurosci 30: 47-58.

Dodelet VC, Pazzagli C, Zisch AH, Hauser CA, Pasquale EB. 1999. A novel signaling intermediate, SHEP1, directly couples Eph receptors to R-Ras and Rap1A. J Biol Chem 274: 31941-31946.

Dotti CG, Sullivan CA, Banker GA. 1988. The establishment of polarity by hippocampal neurons in culture. J Neurosci 8: $1454-1468$

Estrach S, Schmidt S, Diriong S, Penna A, Blangy A, Fort P, Debant A. 2002. The Human Rho-GEF trio and its target GTPase RhoG are involved in the NGF pathway, leading to neurite outgrowth. Curr Biol 12: 307-312.

Fan X, Labrador JP, Hing H, Bashaw GJ. 2003. Slit stimulation recruits Dock and Pak to the roundabout receptor and increases Rac activity to regulate axon repulsion at the CNS midline. Neuron 40: 113-127.

Fivaz M, Bandara S, Inoue T, Meyer T. 2008. Robust neuronal symmetry breaking by Ras-triggered local positive feedback. Curr Biol 18: 44-50.

Fritz JL, VanBerkum MF. 2002. Regulation of rho family GTPases is required to prevent axons from crossing the midline. Dev Biol 252: 46-58.

Fukata M, Nakagawa M, Kaibuchi K. 2003. Roles of Rhofamily GTPases in cell polarisation and directional migration. Curr Opin Cell Biol 15: 590-597. 
Fukata Y, Itoh TJ, Kimura T, Menager C, Nishimura T, Shiromizu T, Watanabe $\mathrm{H}$, Inagaki $\mathrm{N}$, Iwamatsu A, et al.. 2002. CRMP-2 binds to tubulin heterodimers to promote microtubule assembly. Nat Cell Biol 4: 583-591.

Gallo G. 2006. RhoA-kinase coordinates F-actin organization and myosin II activity during semaphorin3A-induced axon retraction. J Cell Sci 119: 3413-3423.

Gartner A, Huang X, Hall A. 2006. Neuronal polarity is regulated by glycogen synthase kinase-3 (GSK-3 $\beta$ ) independently of Akt/PKB serine phosphorylation. J Cell Sci 119: 3927-3934.

Garvalov BK, Flynn KC, Neukirchen D, Meyn L, Teusch N, Wu X, Brakebusch C, Bamburg JR, Bradke F. 2007. Cdc42 regulates cofilin during the establishment of neuronal polarity. J Neurosci 27: 13117-13129.

Goldstein B, Macara IG. 2007. The PAR proteins: Fundamental players in animal cell polarization. Dev Cell 13: 609-622.

Goldstein AY, Jan YN, Luo L. 2005. Function and regulation of Tumbleweed (RacGAP50C) in neuroblast proliferation and neuronal morphogenesis. Proc Natl Acad Sci 102: 3834-3839.

Govek EE, Newey SE, Van Aelst L. 2005. The role of the Rho GTPases in neuronal development. Genes Dev 19: 1-49.

Guan KL, Rao Y. 2003. Signalling mechanisms mediating neuronal responses to guidance cues. Nat Rev Neurosci 4: 941-956.

Hakeda-Suzuki S, Ng J, Tzu J, Dietzl G, Sun Y, Harms M, Nardine T, Luo L, Dickson BJ. 2002. Rac function and regulation during Drosophila development. Nature 416: $438-442$.

Harrington AW, Li QM, Tep C, Park JB, He Z, Yoon SO. 2008. The role of Kalirin9 in p75/nogo receptormediated RhoA activation in cerebellar granule neurons. J Biol Chem 283: 24690-24697.

Hu H, Marton TF, Goodman CS. 2001. Plexin B mediates axon guidance in Drosophila by simultaneously inhibiting active Rac and enhancing RhoA signaling. Neuron 32: $39-51$

Hu H, Li M, Labrador JP, McEwen J, Lai EC, Goodman CS, Bashaw GJ. 2005. Cross GTPase-activating protein (CrossGAP)/Vilse links the Roundabout receptor to Rac to regulate midline repulsion. Proc Natl Acad Sci 102: 4613-4618.

Ito Y, Oinuma I, Katoh H, Kaibuchi K, Negishi M. 2006. Sema4D/plexin-B1 activates GSK-3ßthrough R-Ras GAP activity, inducing growth cone collapse. $E M B O$ Rep 7: 704-709.

Iwasato T, Katoh H, Nishimaru H, Ishikawa Y, Inoue H, Saito YM, Ando R, Iwama M, Takahashi R, Negishi M, et al. 2007. Rac-GAP alpha-chimerin regulates motor-circuit formation as a key mediator of EphrinB3/EphA4 forward signaling. Cell 130: 742-753.

Jacobs T, Causeret F, Nishimura YV, Terao M, Norman A, Hoshino M, Nikolic M. 2007. Localized activation of p21-activated kinase controls neuronal polarity and morphology. J Neurosci 27: 8604-8615.

Jaffe AB, Hall A. 2005. Rho GTPases: Biochemistry and biology. Annu Rev Cell Dev Biol 21: 247-269.

Jin Z, Strittmatter SM. 1997. Rac1 mediates collapsin-1induced growth cone collapse. J Neurosci 17: 6256-6263.
Jurney WM, Gallo G, Letourneau PC, McLoon SC. 2002. Rac1-mediated endocytosis during ephrin-A2- and semaphorin 3A-induced growth cone collapse. J Neurosci 22: 6019-6028.

Kakimoto T, Katoh H, Negishi M. 2006. Regulation of neuronal morphology by Toca-1, an F-BAR/EFC protein that induces plasma membrane invagination. $J$ Biol Chem 281: 29042-29053.

Kalil K, Szebenyi G, Dent EW. 2000. Common mechanisms underlying growth cone guidance and axon branching. $J$ Neurobiol 44: 145-158.

Kassai H, Terashima T, Fukaya M, Nakao K, Sakahara M, Watanabe M, Aiba A. 2008. Rac1 in cortical projection neurons is selectively required for midline crossing of commissural axonal formation. Eur J Neurosci 28: 257-267.

Katoh H, Negishi M. 2003. RhoG activates Racl by direct interaction with the Dock180-binding protein Elmo. Nature 424: 461-464.

Kaufmann N, Wills ZP, Van Vactor D. 1998. Drosophila Racl controls motor axon guidance. Development 125: 453-461.

Kim MD, Kamiyama D, Kolodziej P, Hing H, Chiba A. 2003. Isolation of Rho GTPase effector pathways during axon development. Dev Biol 262: 282-293.

Kim WY, Zhou FQ, Zhou J, Yokota Y, Wang YM, Yoshimura T, Kaibuchi K, Woodgett JR, Anton ES, Snider WD. 2006. Essential roles for GSK-3s and GSK-3-primed substrates in neurotrophin-induced and hippocampal axon growth. Neuron 52: 981-996.

Kruger RP, Aurandt J, Guan KL. 2005. Semaphorins command cells to move. Nat Rev 6: 789-800.

Kuhn TB, Brown MD, Wilcox CL, Raper JA, Bamburg JR. 1999. Myelin and collapsin-1 induce motor neuron growth cone collapse through different pathways: Inhibition of collapse by opposing mutants of racl. J Neurosci 19: 1965-1975.

Lalli G. 2009. RalA and the exocyst complex influence neuronal polarity through PAR-3 and aPKC. J Cell Sci 122: 1499-1506.

Lalli G, Hall A. 2005. Ral GTPases regulate neurite branching through GAP-43 and the exocyst complex. J Cell Biol 171: 857-869.

Lee T, Winter C, Marticke SS, Lee A, Luo L. 2000. Essential roles of Drosophila RhoA in the regulation of neuroblast proliferation and dendritic but not axonal morphogenesis. Neuron 25: 307-316.

Lein PJ, Guo X, Shi GX, Moholt-Siebert M, Bruun D, Andres DA. 2007. The novel GTPase Rit differentially regulates axonal and dendritic growth. $J$ Neurosci 27: $4725-4736$.

Li YH, Werner H, Puschel AW. 2008b. Rheb and mTOR regulate neuronal polarity through Rap1B. J Biol Chem 283: 33784-33792.

Li X, Gao X, Liu G, Xiong W, Wu J, Rao Y. 2008a. Netrin signal transduction and the guanine nucleotide exchange factor DOCK180 in attractive signaling. Nat Neurosci 11: $28-35$.

Li X, Meriane M, Triki I, Shekarabi M, Kennedy TE, Larose L, Lamarche-Vane N. 2002a. The adaptor protein Nck-1 couples the netrin-1 receptor DCC (deleted in colorectal 
cancer) to the activation of the small GTPase Racl through an atypical mechanism. J Biol Chem 277: 37788-37797.

Li X, Saint-Cyr-Proulx E, Aktories K, Lamarche-Vane N. 2002b. Rac1 and Cdc42 but not RhoA or Rho kinase activities are required for neurite outgrowth induced by the Netrin-1 receptor DCC (deleted in colorectal cancer) in N1E-115 neuroblastoma cells. J Biol Chem 277: 15207-15214.

Lundquist EA. 2003. Rac proteins and the control of axon development. Curr Opin Neurobiol 13: 384-390.

Lundquist EA, Reddien PW, Hartwieg E, Horvitz HR, Bargmann CI. 2001. Three C. elegans Rac proteins and several alternative Rac regulators control axon guidance, cell migration and apoptotic cell phagocytosis. Development 128: $4475-4488$.

Luo L, Hensch TK, Ackerman L, Barbel S, Jan LY, Jan YN. 1996. Differential effects of the Rac GTPase on Purkinje cell axons and dendritic trunks and spines. Nature 379: 837-840.

Luo L, Liao YJ, Jan LY, Jan YN. 1994. Distinct morphogenetic functions of similar small GTPases: Drosophila Drac1 is involved in axonal outgrowth and myoblast fusion. Genes Dev 8: 1787-1802.

Markus A, Zhong J, Snider WD. 2002. Raf and akt mediate distinct aspects of sensory axon growth. Neuron 35: 65-76.

Mimura F, Yamagishi S, Arimura N, Fujitani M, Kubo T, Kaibuchi K, Yamashita T. 2006. Myelin-associated glycoprotein inhibits microtubule assembly by a Rho-kinasedependent mechanism. J Biol Chem 281: 15970-15979.

Moore SW, Tessier-Lavigne M, Kennedy TE. 2007. Netrins and their receptors. Adv Exp Med Biol 621: 17-31.

Neumann H, Schweigreiter R, Yamashita T, Rosenkranz K, Wekerle H, Barde YA. 2002. Tumor necrosis factor inhibits neurite outgrowth and branching of hippocampal neurons by a rho-dependent mechanism. J Neurosci 22 : 854-862.

Newsome TP, Schmidt S, Dietzl G, Keleman K, Asling B, Debant A, Dickson BJ. 2000. Trio combines with dock to regulate Pak activity during photoreceptor axon pathfinding in Drosophila. Cell 101: 283-294.

Ng J, Luo L. 2004. Rho GTPases regulate axon growth through convergent and divergent signaling pathways. Neuron 44: 779-793.

Ng J, Nardine T, Harms M, Tzu J, Goldstein A, Sun Y, Dietzl G, Dickson BJ, Luo L. 2002. Rac GTPases control axon growth, guidance and branching. Nature 416: 442-447.

Nishimura T, Yamaguchi T, Kato K, Yoshizawa M, Nabeshima Y, Ohno S, Hoshino M, Kaibuchi K. 2005. PAR-6-PAR-3 mediates Cdc42-induced Rac activation through the Rac GEFs STEF/Tiam1. Nat Cell Biol 7: 270-277.

Ohnami S, Endo M, Hirai S, Uesaka N, Hatanaka Y, Yamashita T, Yamamoto N. 2008. Role of RhoA in activitydependent cortical axon branching. J Neurosci 28: 9117-9121.

Oinuma I, Katoh H, Negishi M. 2007. R-Ras controls axon specification upstream of glycogen synthase kinase$3 \beta$ through integrin-linked kinase. J Biol Chem 282: 303-318.
Oinuma I, Ishikawa Y, Katoh H, Negishi M. 2004a. The Semaphorin $4 \mathrm{D}$ receptor Plexin-B1 is a GTPase activating protein for R-Ras. Science 305: 862-865.

Oinuma I, Katoh H, Negishi M. 2004b. Molecular dissection of the semaphorin $4 \mathrm{D}$ receptor plexin-B1-stimulated R-Ras GTPase-activating protein activity and neurite remodeling in hippocampal neurons. J Neurosci 24: 11473-11480.

Polleux F, Snider W. 2010. Initiating and growing an axon. Cold Spring Harb Perspect Biol 2: a001925.

Qu J, Li X, Novitch BG, Zheng Y, Kohn M, Xie JM, Kozinn S, Bronson R, Beg AA, Minden A. 2003. PAK4 kinase is essential for embryonic viability and for proper neuronal development. Mol Cell Biol 23: 7122-7133.

Reber M, Hindges R, Lemke G. 2007. Eph receptors and ephrin ligands in axon guidance. Adv Exp Med Biol 621: $32-49$.

Richter M, Murai KK, Bourgin C, Pak DT, Pasquale EB. 2007. The EphA4 receptor regulates neuronal morphology through SPAR-mediated inactivation of Rap GTPases. J Neurosci 27: 14205-14215.

Romero MI, Lin L, Lush ME, Lei L, Parada LF, Zhu Y. 2007. Deletion of Nf1 in neurons induces increased axon collateral branching after dorsal root injury. $J$ Neurosci 27: 2124-2134.

Rudolph JL, Shi GX, Erdogan E, Fields AP, Andres DA. 2007. Rit mutants confirm role of MEK/ERK signaling in neuronal differentiation and reveal novel Par6 interaction. Biochim Biophys Acta 1773: 1793-1800.

Sahin M, Greer PL, Lin MZ, Poucher H, Eberhart J, Schmidt S, Wright TM, Shamah SM, O'Connell S, Cowan CW, et al. 2005. Eph-dependent tyrosine phosphorylation of ephexin1 modulates growth cone collapse. Neuron 46: 191-204.

Schmidt A, Hall A. 2002. Guanine nucleotide exchange factors for Rho GTPases: Turning on the switch. Genes Dev 16: $1587-1609$.

Schwab ME. 2004. Nogo and axon regeneration. Curr Opin Neurobiol 14: 118-124.

Schwamborn JC, Puschel AW. 2004. The sequential activity of the GTPases Rap1B and Cdc42 determines neuronal polarity. Nat Neurosci 7: 923-929.

Scita G, Confalonieri S, Lappalainen P, Suetsugu S. 2008. IRSp53: Crossing the road of membrane and actin dynamics in the formation of membrane protrusions. Trends Cell Biol 18: 52-60.

Shamah SM, Lin MZ, Goldberg JL, Estrach S, Sahin M, Hu L, Bazalakova M, Neve RL, Corfas G, Debant A, et al. 2001. EphA receptors regulate growth cone dynamics through the novel guanine nucleotide exchange factor ephexin. Cell 105: 233-244.

Shekarabi M, Kennedy TE. 2002. The netrin-1 receptor DCC promotes filopodia formation and cell spreading by activating Cdc42 and Rac1. Mol Cell Neurosci 19: $1-17$.

Shekarabi M, Moore SW, Tritsch NX, Morris SJ, Bouchard JF, Kennedy TE. 2005. Deleted in colorectal cancer binding netrin-1 mediates cell substrate adhesion and recruits Cdc42, Rac1, Pak1, and N-WASP into an intracellular signaling complex that promotes growth cone expansion. $J$ Neurosci 25: 3132-3141. 
A. Hall and G. Lalli

Shi L, Fu WY, Hung KW, Porchetta C, Hall C, Fu AK, Ip NY 2007. a $\alpha$-chimaerin interacts with EphA4 and regulates EphA4-dependent growth cone collapse. Proc Natl Acad Sci 104: 16347-16352.

Shi SH, Cheng T, Jan LY, Jan YN. 2004. APC and GSK-3 $\beta$ are involved in mPar3 targeting to the nascent axon and establishment of neuronal polarity. Curr Biol 14: 2025-2032.

Strasser GA, Rahim NA, VanderWaal KE, Gertler FB, Lanier LM. 2004. Arp2/3 is a negative regulator of growth cone translocation. Neuron 43: 81-94.

Swiercz JM, Kuner R, Behrens J, Offermanns S. 2002. Plexin-B1 directly interacts with PDZ-RhoGEF/LARG to regulate RhoA and growth cone morphology. Neuron 35: $51-63$

Tanabe K, Tachibana T, Yamashita T, Che YH, Yoneda Y, Ochi T, Tohyama M, Yoshikawa H, Kiyama H. 2000. The small GTP-binding protein TC10 promotes nerve elongation in neuronal cells, and its expression is induced during nerve regeneration in rats. $J$ Neurosci 20: 4138-4144.

Thies E, Davenport RW. 2003. Independent roles of Rho-GTPases in growth cone and axonal behavior. J Neurobiol 54: 358-369.

Toyofuku T, Yoshida J, Sugimoto T, Zhang H, Kumanogoh A, Hori M, Kikutani H. 2005. FARP2 triggers signals for Sema3A-mediated axonal repulsion. Nat Neurosci 8: 1712-1719.

Turner LJ, Nicholls S, Hall A. 2004. The activity of the plexin-A1 receptor is regulated by Rac. J Biol Chem 279: 33199-33205.

Uesugi K, Oinuma I, Katoh H, Negishi M. 2009. Different requirement for Rnd GTPases of R-Ras GAP activity of Plexin-C1 and Plexin-D1. J Biol Chem 284: 6743-6751.

Vastrik I, Eickholt BJ, Walsh FS, Ridley A, Doherty P. 1999. Sema3A-induced growth-cone collapse is mediated by Racl amino acids 17-32. Curr Biol 9: 991-998.

Vikis HG, Li W, Guan KL. 2002. The plexin-B1/Rac interaction inhibits PAK activation and enhances Sema4D ligand binding. Genes Dev 16: 836-845.

Wahl S, Barth H, Ciossek T, Aktories K, Mueller BK. 2000. Ephrin-A5 induces collapse of growth cones by activating Rho and Rho kinase. J Cell Biol 149: 263-270.
Wang KC, Kim JA, Sivasankaran R, Segal R, He Z. 2002. P75 interacts with the Nogo receptor as a co-receptor for Nogo, MAG and OMgp. Nature 420: 74-78.

Wang S, Watanabe T, Noritake J, Fukata M, Yoshimura T, Itoh N, Harada T, Nakagawa M, Matsuura Y, Arimura N, et al. 2007. IQGAP3, a novel effector of Racl and Cdc42, regulates neurite outgrowth. J Cell Sci 120: 567-577.

Watabe-Uchida M, John KA, Janas JA, Newey SE, Van Aelst L. 2006. The Rac activator DOCK7 regulates neuronal polarity through local phosphorylation of stathmin/ Op18. Neuron 51: 727-739.

Witte H, Bradke F. 2008. The role of the cytoskeleton during neuronal polarization. Curr Opin Neurobiol 18: 479-487.

Wu KY, Hengst U, Cox LJ, Macosko EZ, Jeromin A, Urquhart ER, Jaffrey SR. 2005. Local translation of RhoA regulates growth cone collapse. Nature 436: 1020-1024.

Yamashita T, Tohyama M. 2003. The p75 receptor acts as a displacement factor that releases Rho from Rho-GDI. Nat Neurosci 6: 461-467.

Yang L, Bashaw GJ. 2006. Son of sevenless directly links the Robo receptor to rac activation to control axon repulsion at the midline. Neuron 52: 595-607.

Zallen JA, Peckol EL, Tobin DM, Bargmann CI. 2000. Neuronal cell shape and neurite initiation are regulated by the Ndr kinase SAX-1, a member of the Orb6/ COT-1/warts serine/threonine kinase family. Mol Biol Cell 11: 3177-3190.

Zanata SM, Hovatta I, Rohm B, Puschel AW. 2002. Antagonistic effects of Rnd1 and RhoD GTPases regulate receptor activity in Semaphorin 3A-induced cytoskeletal collapse. J Neurosci 22: 471-477.

Zhang X, Zhu J, Yang GY, Wang QJ, Qian L, Chen YM, Chen F, Tao Y, Hu HS, Wang T, et al. 2007. Dishevelled promotes axon differentiation by regulating atypical protein kinase C. Nat Cell Biol 9: 743-754.

Zhou FQ, Snider WD. 2005. Cell biology. GSK-3beta and microtubule assembly in axons. Science 308: 211-214.

Zhou FQ, Zhou J, Dedhar S, Wu YH, Snider WD. 2004. NGF-induced axon growth is mediated by localized inactivation of GSK-3beta and functions of the microtubule plus end binding protein APC. Neuron 42: 897-912. 


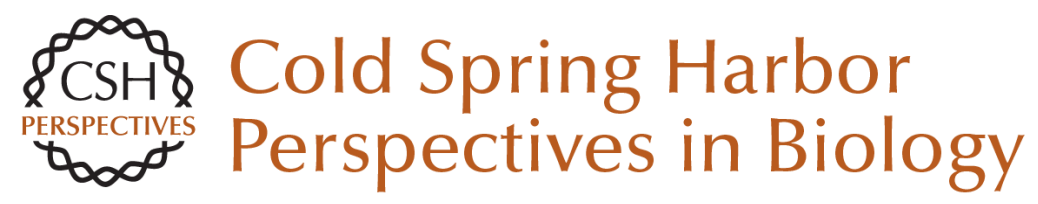

\section{Rho and Ras GTPases in Axon Growth, Guidance, and Branching}

Alan Hall and Giovanna Lalli

Cold Spring Harb Perspect Biol 2010; doi: 10.1101/cshperspect.a001818 originally published online January 27, 2010

\section{Subject Collection}

For additional articles in this collection, see http://cshperspectives.cshlp.org/cgi/collection/

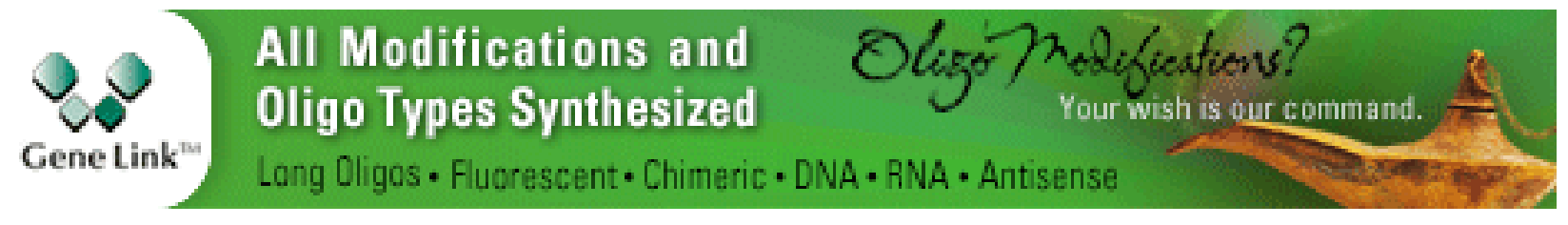

Copyright @ 2010 Cold Spring Harbor Laboratory Press; all rights reserved 